\title{
COMPLIANCE Y SELF-CLEANING EN LA CONTRATACIÓN PÚBLICA (ESPECIAL REFERENCIA AL DERECHO COMUNITARIO EUROPEO) 1
}

\author{
COMPLIANCE AND SELF-CLEANING IN PUBLIC \\ PROCUREMENT (SPECIAL REFERENCE TO EUROPEAN \\ COMMUNITY LAW)
}

Jaime Rodríguez-Arana Muñoz ${ }^{2}$

\begin{abstract}
Recebido em: Aceito em: -

jaime.rodriguezarana.munoz@udc.es

Resumo: La contratación pública es una de las causa de la corrupción. Además de la dimensión punitiva es necesario explorar otras aproximaciones que parten de la perspectiva preventiva. Son las técnicas de compliance y de self-cleaning, de inspiración anglosajona. La Unión Europea acaba de regular en su Directiva de contratación pública de 2014 el selfcleaning estableciendo una serie de características que deberán ser desarrolladas por los Estados Miembros.
\end{abstract}

Palavras-chave: Contratacion pública. Lucha contra la Corrupción. Derecho Comparado. Compliance. Self-cleaning.

\begin{abstract}
Public procurement is one of the causes for corruption. In addition to the punitive aspect, it is necessary to study other approaches that address the preventive aspect. These would be the compliance and self-cleaning techniques, originating in English-speaking countries. The European Union has just regulated self-cleaning in its public procurement Directive from 2014, establishing a series of characteristics to be developed by the Member States.
\end{abstract}

Keywords: Public procurement. Fight against Corruption. Comparative Law. Compliance. Selfcleaning.

\section{INTRODUÇÃO}

Los resultados de la lucha contra la corrupción aconsejan, hoy más que nunca, explorar la virtualidad operativa de las denominadas técnicas preventivas y precautorias para detener esta terrible lacra social que, poco a poco, carcome los fundamentos de la vida democrática y nos conduce a una pérdida inquietante del temple cívico de la población. En efecto, junto a la perspectiva represora y sancionadora, es conveniente indagar acerca de las posibilidades de la autorregulación regulada más allá de visiones exclusivamente punitivas también en materia de contratación pública.

La formación de los empleados públicos en los valores del servicio objetivo al interés general debe acompañarse del sólido compromiso de las empresas y sus dirigentes con la efectiva realización y cumplimiento de obligaciones atinentes a la limpieza de la contratación, evitando conductas ilícitas y, sobre todo, esto es lo más importante, asumiendo programas de "Compliance" previos a la contratación y planteando, cuando sea el caso, en supuestos de prohibición o exclusión para contratar, de exigentes compromisos de self-cleaning, de autosaneamiento, que realmente garanticen la actuación empresarial con arreglo a exigentes criterios deontológicos.

\footnotetext{
${ }^{1}$ Texto publicado originalmente na língua inglesa.

${ }^{2}$ Universidad da Coruña - UDC - Coruña - Espanha
} 
La cultura empresarial, especialmente en los países anglosajones, incluye, como es sabido, dentro de la buena administración y del buen gobierno corporativo, exigentes programas de "Compliance". Medidas y acuerdos que en EEUU desde 2008 constituyen incluso requisitos para contratar con las Administraciones públicas. En la Unión Europea las Directivas de 2014, debido a la influencia británica y a la experiencia austríaca y alemana, reconocen compromisos de self-cleaning para levantar determinadas prohibiciones o exclusiones para contratar cuando los órganos competentes comprueben que las pruebas de fiabilidad ofrecidas por las empresas son serias y solventes. Es más, la Unión Europea configura como derecho del contratista incurso en causa de exclusión o prohibición para contratar con la Administración pública su levantamiento, su rehabilitación, como consecuencia del compromiso de autosaneamiento, de integridad. Eso sí, siempre que sea fiable a juicio del órgano competente para evaluar tal posibilidad, algo que será excepcional pero que en determinados supuestos, siempre que se motive adecuadamente, hasta puede ser coherente con el servicio objetivo al interés general.

Las medidas para combatir la corrupción en la contratación pública, como es bien sabido, se han desarrollado de manera significativa en los últimos años tras la constatación de ser éste uno de los sectores más proclives a la proliferación de prácticas ilícitas. Los incumplimientos más graves de los deberes de objetividad e imparcialidad en la búsqueda del interés general son merecedores de reproche penal y de su condena pueden derivarse consecuencias administrativas tales como impedir adjudicar un contrato público a quienes hayan sido condenados por determinados delitos. Ahora bien, con independencia de la perspectiva punitiva, necesaria, un marco integral de lucha contra la corrupción exige además poner el acento en la prevención. Por ello, las acciones a emprender desde la normativa contractual deben centrarse en un enfoque preventivo que vincule tanto a la Administración como al ámbito empresarial y que evite el desvío de fondos públicos hacia intereses privados espurios.

Una regeneración en la gestión de los recursos públicos se debe llevar a cabo desde una mayor formación e independencia de las personas encargadas de la adjudicación contractual, pero también fomentando medidas de autorregulación que incrementen los controles internos en las propias empresas poniendo obstáculos a posibles conductas ilícitas. Esta posibilidad se encuentra refrendada por la OCDE y expresamente autorizada en los países anglosajones que se muestran favorables a considerar los programas de cumplimiento normativo (Compliance), los códigos internos de comportamiento ético y la adopción de pactos de integridad en las compras públicas.

Las nuevas Directivas europeas sobre contratación pública del año 2014 también incorporan instrumentos normativos dirigidos a prevenir y enfrentar los delitos cometidos por las empresas a través de las llamadas medidas autocorrectoras, de autolimpieza o de «self-cleaning». La puesta en práctica de estas medidas supone un derecho para el operador económico de excepcionar la aplicación de una prohibición de contratar cuando pueda probar que ha adoptado mecanismos eficaces para corregir las consecuencias de su inadecuado comportamiento e impedir de manera efectiva que éste se vuelva a repetir.

La Administración pública actúa ordinariamente de forma unilateral y en ocasiones acude a la sociedad para reclamar su colaboración para prestar servicios públicos o construir infraestructuras 
públicas que mejoren la calidad de vida de las personas. Para cumplir sus fines, también en materia de contratación, la Administración pública precisa realizar su tarea de forma adecuada y pertinente, sirviendo permanente y objetivamente el interés general.

Pues bien, constatadas relevantes insuficiencias y disfuncionalidades relevantes en el funcionamiento y actividad de las Administraciones públicas, surge el debate acerca de la necesidad de contar con aparatos y estructuras públicas que trabajen con equidad, con imparcialidad, con sensibilidad social y que sean capaces de resolver los asuntos en plazos razonables. En este sentido, se comprende fácilmente que una Administración caracterizada de esta manera esté en las mejores condiciones posibles para hacer posible el libre y solidario desarrollo de la personalidad de todos los ciudadanos.

La buena administración trae consigo la necesidad de prevenir la corrupción en la contratación pues, por ejemplo en el ámbito de la Unión Europea, es una de las causas, junto al urbanismo y la financiación de los partidos políticos, que desencadena esta lacra social que solo en el año 2014 se cobró 120.000 millones de euros.

La lucha contra la corrupción, también en materia contractual no es, sin embargo, un fin en sí misma. Es un medio para que los ciudadanos puedan disfrutar de obras públicas, de servicios públicos que les permitan vivir en mejores condiciones, que les permitan también elegir de entre varias opciones aquella que mejor se adecue a sus necesidades. La Unión Europea parte de la premisa de la existencia de un mercado abierto, plural, competitivo. Por eso la propia directiva termina el régimen de las exclusiones para contratar reconociendo las llamadas técnicas de selfcleaning, los compromisos de integridad o probidad que pueden ser necesarios cuándo, efectivamente, se pongan en cuestión las más elementales reglas que deben caracterizar al sistema de mercado en economías presididas, como es el caso de la Unión Europea, por los principios del Estado social y democrático de Derecho.

\section{LOS COMPROMISOS DE COMPLIANCE EN LA LUCHA ANTICORRUPCIÓN: SENTIDO Y FUNCIONALIDAD}

Desde una perspectiva unilateral, la sanción frente a los casos de corrupción constituye la prohibición o exclusión para contratar y, es, desde luego, la solución clásica al problema. Sin embargo, junto a la necesidad de castigar el ilícito penal o administrativo, es menester también tener presente que, desde el pensamiento abierto, dinámico y compatible, es menester integrar otros factores en esta cuestión como puede ser la garantía de un mercado competitivo que ofrezca buenos servicios y buenas obras públicas. Por eso, como veremos, una vez una que una empresa se encuentra incursa en una causa de prohibición o exclusión para contratar, en la Unión Europea existe el derecho del contratista, en un determinado marco, a solicitar que el órgano competente compruebe que ha adoptado las medidas adecuadas para ser fiable como contratista de la Administración pública.

Estas medidas de self-clening o de auotosaneamiento, son un remedio extraordinario para empresas incursas en causas de exclusión o de prohibición para contratar. Sin embargo, si se genera 
una cultura de la prevención pertinente e inteligente, hasta se podría pensar, como acontece en los Estados Unidos de Norteamérica, que la emisión de compromisos de "Compliance" por las empresas sea requisito para ser admitido a una licitación pública ${ }^{3}$. Es decir, los programas de "Compliance", además de atenuar la responsabilidad penal de la empresa contratista ante los daños causados por su personal en nombre y por cuenta de la empresa, pueden ser medios eficaces para asegurar el cumplimiento de las obligaciones, jurídicas y éticas, por parte del contratista.

$\mathrm{Ni}$ que decir tiene que frente a una razonable política de promoción de programas de "Compliance" por parte de los contratistas, es necesaria también la existencia de códigos de conducta, de buenas prácticas por parte de la Administración, por parte de los funcionarios que integran las mesas de contratación, por el personal al servicio de la Administración pública que forma parte de los Poderes adjudicadores. Esto es, hay que seguir programas de Compliance por ambas partes pues la corrupción, no lo olvidemos, es cosa de dos. Por cierto, los órganos de contratación y los Poderes adjudicadores, al igual que los Tribunales y Comisiones encargadas de la selección de personal al servicio de la Administración pública, deben estar integrados exclusivamente por personal no político. De otra manera, no se estaría atajando creíblemente la corrupción.

Si como parece el hecho de que las empresas dispongan de programas de "Compliance" para detectar la existencia de comportamientos y conductas ilícitas y de ponerlas en conocimiento de la Administración, atenúa la responsabilidad penal de las empresas, es lógico, deseable, que se establezca como una exigencia de contratación que las empresas contratistas de la Administración pública tengan un sistema de "Compliance" efectivo y en vigor al momento de enviar sus ofertas ${ }^{4}$. En este sentido, ha sido constante, dice GÓMEZ-JARA, la inclinación de la doctrina especializada hacia estas prácticas pues la instauración de estos programas en los que resultan indispensables sistemas de denuncias internas, nombramiento de un oficial de cumplimiento, reacciones post-delictivas de investigación de los hechos denunciados, formación continuada, etc, son una necesidad para una mejor y más justar imputación o des imputación de los contratistas y también, por supuesto, para evitar la comisión de delitos ${ }^{5}$.

Esta tendencia, que se nos antoja imparable, es consecuencia, no sólo de la operatividad de la denominada autorregulación regulada, sino de las exigencias del pensamiento abierto, dinámico y compatible aplicado a la lucha anticorrupción. Es decir, la colaboración de las empresas es fundamental para vencer a la corrupción. Para ello, es menester que se instalen estos programas de cumplimiento. Unos programas llamados a prevenir y detectar las conductas ilícitas ${ }^{6}$. Prevención y detección precoz son dos armas fundamentales en el combate a la corrupción que estos

\footnotetext{
${ }^{3}$ Vid. Government Compliance Handbook, 4o edición, 2012.

${ }^{4}$ C. GÓMEZ-JARA DÍEZ, La responsabilidad penal de las personas jurídicas en el ámbito público:¿ hacia los coplinace programs "anti-corrupción" como exigencias legales de contratación pública?, en A. PALOMAR OJEDA/M. GARCÉS SANAGUSTín (Directores), La gestión de los fondos públicos: control y responsabilidades, Aranzadi-Thomson, Madrid, 2013, p. 1236

${ }^{5}$ ES decir, estas prácticas, dice GÓMEZ-JARA..., p. 1247, constituyen un marcado incentivo para que las organizaciones adopten o implementen de manera efectiva dichos programas de cumplimiento puesto que constituyen su herramienta de defensa más evidente frente a una eventual imputación de responsabilidad penal.

${ }^{6}$ Vid. J. ALONSO GALLO, Los programas de cumplimiento, en J. DÍAZ MAROTO (Coordinador), Estudios sobre la reforma del Código Penal, Madrid, 2011, pp, 141 y ss.
} 
instrumentos, cuando se implementan con rigor y seriedad, con sistemas de evaluación y seguimiento eficaces, realmente pueden obtener mejores resultados que la dimensión exclusivamente penal o punitiva.

Por ello, pensamos que en la implementación que se haga en el Reino de España de las Directivas de 2014 bien podría establecerse que como requisito sine qua non para poder presentarse a licitaciones públicas, las empresas presenten programas de Compliance solventes que deberían ser juzgados por Comisiones independientes establecidas al efecto integradas por personas de reconocido prestigio en la materia.

La estrategia de "Compliance" parte de la autorregulación y busca evitar el incumplimiento de las normas y, por supuesto, de las obligaciones que caracterizan la posición jurídica de quien contrata con la Administración pública.

En Estados Unidos desde 2008 es menester para contratar con la Administración pública contar con un programa de cumplimiento anti-corrupción ${ }^{7}$. Tal medida trae su causa de la experiencia de los programas de buen gobierno corporativo en el sector privado. Al igual que aconteciera con la introducción de códigos éticos al interior del sector público, que se establecieron a imagen y semejanza de lo que acontecía en el sector privado (management cualitativo) ${ }^{8}$, ahora, tras constatar el fracaso de la perspectiva exclusivamente punitiva en el combate a la corrupción, se buscan otros caminos más complementarios y compatibles y se acude "mutatis mutandis" a estos programas de cumplimiento en el sector privado $^{9}$ adaptados, es lógico, a negocios en los que prima el interés general, como son los contratos públicos, una categoría jurídico-administrativa que, como queda expuesto, es expresión de la política pública de un Estado definido como social y democrático de Derecho.

La tendencia a la progresiva implementación de estos programas de cumplimiento anticorrupción tuvo su apogeo en EEUU tras los escándalos de todos conocidos protagonizados por relevantes contratistas durante las operaciones militares desarrolladas en Irak y Afganistán, en las que asuntos de obvio interés general relativos a la seguridad se confiaron al sector privado.

En esta política pro "Compliance" anti-corrupción ha tenido mucho que ver la acción pública del Presidente Obama pues se puede apreciar recientemente el aumento de los procedimientos sancionadores a cargo del Departamento de Justicia de los Estados Unidos, así como el crecimiento exponencial de las denominadas acciones "qui tam"10, en las que personas físicas que denuncian determinados hechos delictivos que conocen en relación con empresas son beneficiarios de un porcentaje de la multa adoptada tras el acuerdo entre la Administración y la compañía ${ }^{11}$.

\footnotetext{
${ }^{7}$ Tal exigencia se repute como imprescindible para los contratos de una cuantía superior a los cinco millones de dólares y a partid del 24 de septiembre d 2007 con carácter general tras las pertinentes reformas de la legislación norteamericana. Cfr. R. SCHECHTER/S. TURNER, New challenges in Government Contractors in an Aggressive Enforcement Environment, en Government Contractors Compliance, 2012, pp. 7 y ss.

${ }^{8}$ Vid. J. RODRIGUEZ-ARANA, La dimensión ética de la función pública, INAP, Madrid, 2013, pp. 25 y ss.

${ }^{9}$ C. GÓMEZ-JARA..., p. 1248. Vid. C. YUNKINS, Enchancing Integrity-Aligning proposed contractor compliance requeriments with broader avances in Corporate Compliance, The Government Contractor 49 (2007), pp. 146 y ss.

${ }^{10}$ Vid. M.H. LEMOS, Special Incentives to Sue, Minnesota Law Review 95 (2011), pp. 782 y ss.

${ }^{11}$ C. GÓMEZ-JARA..., p. 1249.
} 
Estos programas de cumplimiento se fundan sobre cuatro elementos ${ }^{12}$. Primero, integridad al tratar con funcionarios públicos, prohibiéndose expresamente toda promesa, dádiva o recompensas a este personal. Las relaciones entre el licitador o contratista y los funcionarios públicos encargados del procedimiento de adjudicación o de ejecución contractual deben constar por escrito y las conversaciones orales deben estar a disposición de quienes ostenten un interés legítimo en su difusión. Por supuesto, de las reuniones que se mantengan deberá siempre levantarse acta por escrito. En este punto, un asunto relevante que afecta a los conflictos de interés se refiere a la futura contratación del personal funcionario por la empresa una vez incluso que se supere el periodo de gracia en el que tras la salida de la función pública ha d abstenerse de mantener relaciones comerciales o profesionales con compañías con las que ha trabajado de algún modo de su condición de servidor público. En este punto, como en casi todos los que se refieren a la ética de las conductas de los funcionarios públicos, la transparencia y publicidad que ha de caracterizar su actividad y sus relaciones con las empresas privadas, suele resolver siempre cualquier dilema o problema que se plantee.

El segundo de los argumentos sobre los que descansan estos programas de cumplimiento se refiere a la honestidad en el intercambio de información, prohibiéndose, es lógico, las falsedades documentales. Pienso que no solo se debe castigar este tipo penal sino también la puesta en conocimiento de los licitadores de información privilegiada. También debería encajar aquí la prohibición de facilitar más o menos información a unos licitadores que a otros y, por ende, cualquier manejo de la información que no siga las reglas de la objetividad y de la igualdad entre todos los licitadores.

El tercer elemento se refiere a la consolidación de las relaciones éticas con terceros prohibiéndose especialmente las comisiones ilícitas o Kicks-backs, hoy lamentablemente una práctica habitual en esta materia. El fortalecimiento ético pasa, en este tema, por mantener elevados estándares éticos en las denominadas subcontrataciones, muchas veces un mundo opaco e ignoto en el que se realizan grandes intercambios financieros al margen de la ética y la legalidad.

En cuarto y último lugar, estos programas de cumplimiento anti-corrupción deben fomentar la competencia leal evitándose toda suerte de prácticas encaminadas a que los licitadores o el marco jurídico general expresen subjetividad o favoritismo ${ }^{13}$.

Estos programas de cumplimiento anti-corrupción en materia contractual en los EEUU deben contener un mapa de riesgo, que es un análisis acerca de las principales áreas de corrupción que amenazan a una empresa. También el plan de Compliance debe contar con un Código de buena conducta que identifique buenas prácticas, un Código que debe elaborarse con la colaboración de los directivos y de los empleados de las empresas y que debe ser objeto de revisión periódica y de formación continuada.

Junto a la existencia de códigos de conducta y de buenas prácticas, los programas de "Compliance" anti-corrupción deben disponer de revisiones periódicas que aseguran su efectiva implantación y realización. Es decir, los contratistas deben verificar periódicamente que el programa

\footnotetext{
12 Ibidem.

${ }^{13}$ Vid. A.B. STYLES, Developing Effective, Transparent Compliance Program for Government Contractors, en Government Contractors Compliance, 2012, pp. 89 y ss.
}

Revista do Direito [ISSN 1982-9957]. Santa Cruz do Sul, v. 1, n. 51, p. 36-57, jan./abr. 2017. https://online.unisc.br/seer/index.php/direito/index 
se cumple efectivamente y que, por ello, la sensibilidad ética en la compañía aumenta exponencialmente. Además, y esto es complejo y difícil, cada empresa debe tener un sistema que permita reportar o informar en tiempo a la Administración acerca de conductas ilícitas de personal de la compañía. Para ello se debe garantizar el anonimato y hasta incentivar y premiar estas denuncias pues siempre es preferible el interés general al particular. Los programas de cumplimiento incorporan también, es lógico, la realización de auditorías internas y externas acerca del grado de efectividad del programa y, por supuesto, la adopción de medidas disciplinarias internas cuándos se detectan comportamientos ilícitos. Finalmente, es menester que las empresas contratistas de la Administración en materia contractual colaboren plenamente con la Administración pública competente para perseguir estas conductas ilícitas, ministerio fiscal especialmente.

La exigencia de estos programas de cumplimiento anti-corrupción para las empresas que quieran contratar con la Administración pública en Estados Unidos de Norteamérica implica que han de aplicar respecto de sus empleados un estándar de diligencia debida así como informar a las Autoridades por escrito, adjuntando el material probatorio correspondiente, acerca de aquellas conductas ilegales de fraude, cohecho o cualquier tipo de actividad ilícita que detecten al interior de su propia compañía ${ }^{14}$. Estas regulaciones están modificando cualitativa y sustancialmente la praxis anterior, de forma y manera que han aumentado exponencialmente las denuncias de los contratistas que llegan a las Autoridades públicas. Hasta el punto de que, como señala GÓMEZ-JARA, los Tribunales están comenzando a considerar que la certificación que expresa la inexistencia de conductas ilícitas cuándo el contratistas debía estar al tanto de las mismas consiste una falsedad documental perseguible de oficio por las Autoridades competentes ${ }^{15}$.

Algunas de las cuestiones que las Autoridades consideran relevantes en orden a la eficacia de estos programas de "Compliance" se refieren a si la empresa dispone realmente de mecanismos a través de los cuales los empleados pueden informar de conductas ilícitas, a si existe algún instrumento que preserve la documentación sensible para investigar las conductas denunciadas, a si el contratista adopta medidas adecuadas cuándo el sistema detecta fallos en el sistema de "Compliance", a si el contratista revisa periódicamente la eficacia del procedimiento de control interno y a si el contratista ha declarado y ejecutado una política de no represalias contra los empleados denunciantes $^{16}$.

La experiencia norteamericana nos enseña que fue la regulación penal la que provocó la emergencia en el ámbito público la proliferación de los Compliance program. Programas que en opinión de GÓMEZ-JARA son la única defensa que las empresas contratistas tienen frente a imputaciones de responsabilidad penal por actuaciones de sus empleados en su nombre y representación y con la intención de beneficiarla ${ }^{17}$.

\footnotetext{
${ }^{14}$ Vid. A.B. STYLES, Developing Effective, Transparent Compliance Program for Government Contractors, en Government Contractors Compliance, 2012, pp. 89 y ss.

${ }^{15}$ Ibidem.

${ }^{16}$ Vid. C. GÓMEZ-JARA DIEZ, Corporate Culpability as a Limit to the Overcriminalization of Corporate Criminal Liability: Tehe interplay between Corporate Compliance, Self-regulation and Corporate Citizenship, en New Criminal Law Review 14, 2011, pp. 78 y ss.

${ }^{17}$ C. GÓMEZ-JARA....., p. 1251.
} 
En efecto, en esta dirección se pronuncia GIMENO FELIÚ pues en realidad si queremos que el principio de integridad brille con luz propia en esta materia y disponga de eficacia jurídica, es menester exigir estos programas de Compliance como requisitos para contratar con las Administraciones públicas ${ }^{18}$. En un mundo de legislación motorizada en el que reina la heterogeneidad de las normas, especialmente en materia punitiva, es menester que estos programas de buen gobierno y de buena administración de las empresas se implementen. De forma y manera que esta tarea de asegurar el cumplimiento de las obligaciones de los contratistas permita gestionar las consecuencias de que una compañía pueda sufrir como resultado del incumplimiento de leyes, reglamentos, normas, reglas, o estándares de conducta o comportamiento autorregulados ${ }^{19}$.

\section{SELF-CLEANING EN LA CONTRATACIÓN PÚBLICA: VIRTUALIDADOPERATIVA Y REGULACIÓN EN LA UNION EUROPEA}

La mejor política en la lucha contra la corrupción es su prevención. Si actuamos con eficacia antes de que se produzca interviniendo sobre sus causas y sus motivaciones, esta es más difícil que se produzca. Se trata, pues, de una estrategia ex ante y ex post. Dada la experiencia de estos últimos años en los que la corrupción ha crecido exponencialmente, es menester trabajar en la prevención a través de programas de cumplimiento antes de la adjudicación y, también, a través del fomento del cumplimiento incluso en los casos en que las empresas hayan incurrido en corrupción y estén dispuestas a tomar medidas creíbles y fiables para que no vuelva a acontecer. Este es el marco de operatividad de la llamada estrategia de autosaneamiento, de autolimpieza o self-cleaning que está proliferando en este tiempo, principalmente en los países anglosajones y que la UE acaba de confirmar en sus últimas Directivas de 2014.

En este sentido, la realidad de la corrupción, en algunos países con tintes dramáticos, aconseja que se exploren distintas estrategias que fomenten el cumplimiento por parte de las empresas y también por parte de la Administración pública. La protección de la competitividad del mercado o, lo que es lo mismo, la garantía de las mejores condiciones para que los ciudadanos dispongan de los mejores servicios públicos y las mejores públicas puede aconsejar que excepcionalmente los empresarios incursos en prohibiciones para contratar puedan ser rehabilitados $^{20}$ siempre y cuando la Administración contratante verifique que los compromisos ofrecidos son más que suficientes para evitar la corrupción en el futuro. Es decir, estamos ante

\footnotetext{
${ }^{18}$ J.M. GIMENO FELIÚ, La Reforma comunitaria en materia de contratos públicos y su incidencia en la legislación española: Una visión desde la perspectiva de la integridad, en Las nuevas Directivas de Contratación Pública, Aranzadi-Thomson-Reuters, Cizur menor, Navarra, 2015, pp. 37 y ss, especialmente páginas 94 y ss.

${ }^{19}$ M.A. BERNAL BLAY, Los efectos de los programas de Compliance en la contratación pública, en Las nuevas...., p. 413

${ }^{20}$ S. WILLIAMS ELEGBE, Fighting corruption in public procurement, A comparative analysis of discualification or debarment measures, hart Publishing, 2012, pp. 248 y ss. En opinión de este autor, pueden ser causa del levantamiento de las prohibiciones de contratar la existencia de una necesidad pública de mantener la financiación de empresas incursas en ilícitos penales, tal y como aconteció en los casos $\mathrm{MCI}$ World Com, Boeing e IBM. En este último caso, llama la atención que Boeing estuviera suspendida para licitar en EEUU y que se hubiera levantado la prohibición a los ocho días siempre que se verificara que la suspensión de la penalización tuviera efectos perjudiciales a largo plazo.
} 
actuaciones de los contratistas incursos en corrupción sometidos a condición, que se dará si efectivamente a juicio de la Administración, en un procedimiento administrativo con todas las garantías y con audiencia a los interesados, el interés general aconseja conceder el derecho a la rehabilitación del que dispone el contratista incurso en prohibición de contratar.

Mientas que los programas de cumplimiento anticorrupción operan ordinariamente antes de la contratación, incluso como requisitos para presentarse a la licitación, el autosaneamiento o selfcleaning opera en supuestos relativos a empresas condenadas por corrupción que están dispuestas a rehabilitarse a través de creíbles y fiables medidas de cumplimiento. En el primer caso es una medida general de prevención de la corrupción, en el segundo se trata de actos administrativos de rehabilitación a favor del empresario incurso en corrupción en evitación e conductas ilícitas futuras tras una rigurosa evaluación de las medidas adoptadas por el contratista.

En estos supuestos, la actuación administrativa de comprobación de la credibilidad y solvencia de las medidas adoptadas por el contratista incurso en prohibición se dirige precisamente a declarar que es compatible con el interés general la rehabilitación del contratista. WILLIAMS-ELEGBE hace referencia a la racionalidad de las excepciones a las prohibiciones para contratar, una racionalidad que trae causa precisamente de del interés público, de la seguridad nacional, de las situaciones de emergencia y de las consecuencias económicas del impacto del levantamiento de las prohibiciones $^{21}$.

Tal y como señalan PEREIRA y WALLBACH SCHWIND, estas medidas de self-cleaning, para que no constituyan supuestos de impunidad, deben ser objeto de un examen riguroso y exhaustivo por parte de los órganos de contratación. De no ser así, si se operara en esta materia con superficialidad y frivolidad, hasta estas medidas serían contraproducentes pues la opinión pública se sentiría engañada con toda razón. De ahí que habría que pensar en dar publicidad e información a la ciudadanía de estas medidas con el fin de trabajar culturalmente desde esta óptica preventiva y de exigencia contra la corrupción.

Un análisis en profundidad del que se derivan ordinariamente pesadas cargas para el infractor y alteraciones radicales al interior del contratista que solicita este derecho. En estos supuestos, señalan estos autores, es menester una tarea de contraste jurídico acerca de la idoneidad o no de mantener la actividad empresarial o decantarse por su destrucción. El autosaneamiento, las medidas de self-cleaning no son creíbles ni sólidas sin la existencia de un riguroso plan de eliminación de las causas que produjeron el ilícito penal con el fin de asegurar que no volverán a repetirse ${ }^{22}$. Por eso, el compromiso con el cumplimiento y el combate a la corrupción por parte del contratista es fundamental. Hasta el punto de cuanto más fiables y creíbles sean los compromisos asumidos por el contratista más posibilidades de obtener la rehabilitación.

La clave para comprender la funcionalidad y virtualidad operativa de estas medidas de autosaneamiento reside, como hemos indicado, en la estrategia preventiva en el combate a la corrupción. Una perspectiva que no excluye la dimensión punitiva, ni mucho menos. Si a pesar de la

\footnotetext{
${ }^{21}$ S. WILLIAMS...., p.258

${ }^{22}$ C. PEREIRA/R. WALLBACH-SCHWIND, Autosaneamento (self-cleaning) e reabilitação de empresas no direito brasileiro anticorrupção. Informativo Justen, Pereira, Oliveira e Talamini. Curitiba, no 102, agosto de 2015, disponível em www.justen.com.br/informativo.
} 
prevención se produce la corrupción, entonces incluso la severidad de la reacción penal hasta puede ser más intensa. Es decir, las prohibiciones para contratar, las exclusiones para contratar, la declaración de incapacidad para contratar, ahora más allá de la connotación punitiva ${ }^{23}$, deben comprenderse desde una nueva perspectiva, que la supera y que a la vez la integra.

En este sentido, las nuevas directivas comunitarias aprobadas en 2014, especialmente la número 24, regulan exhaustivamente los conflictos de intereses y establecen reglas y principios dirigidos a promover y facilitar la integridad en todas las fases de la contratación, desde la preparación, hasta la adjudicación, con especial hincapié en la ejecución. Es decir, la buena administración en la materia, exige medidas preventivas y sancionadoras de las prácticas ilícitas que se producen, lamentablemente, en grado creciente en este tiempo. En los Estados Unidos de Norteamérica y en la Unión Europea ahora se trabaja desde esta perspectiva. Una perspectiva menos drástica dirigida a prevenir los daños que podría causar al interés general el contratista incurso en una causa o motivo de prohibición o exclusión para contratar. Si, como señalan PEREIRA y WALLABACH-SCHWIND, ahora, siguiendo las nuevas tendencias del Derecho Comparado, se trata de prevenir los daños es preferible optar por el autosaneamiento ${ }^{24}$ riguroso y exigente pues, además de fortalecer las opciones del poder adjudicador, que en esta hipótesis tendrá más licitantes donde elegir -mercado competitivo real- se puede evitar que una condena eterna a una empresa suponga su destrucción y la pérdida de muchos puestos de trabajo, ajenos a unas prácticas que suelen estar ubicadas en determinados departamentos y áreas de las empresas.

Desde luego no es un tema sencillo porque hasta ahora el criterio tradicional es el punitivo y desde esta óptica es desde la que se contemplan las prohibiciones o exclusiones para contratar. Sin embargo, es menester aproximarse a esta problema desde el pensamiento abierto, plural, dinámico y complementario, teniendo presente la realidad y operando con la razón y el compromiso con la justicia sin olvidar la vinculación de todas las categorías e instituciones del Derecho Administrativo al interés general de un Estado social y democrático d Derecho. Desde estos postulados es necesario diferenciar, como señalan PEREIRA y WALLBACH-SCHWIND, la criminalización de la conducta pasada con la prevención de los daños futuros ${ }^{25}$.

En la regulación europea actual, las nuevas Directivas aprobadas en 2014 establecen exclusiones para contratar, que son medidas que limitan el derecho a participar libremente en procedimientos de licitación. Son medidas administrativas aplicadas por los órganos de contratación para descalificar de los procedimientos de contratación pública a quienes incurran una serie de circunstancias. En realidad adoptan la forma de prohibiciones para contratar y la jurisprudencia del Tribunal Supremo español las ha calificado como medidas de garantía del interés general, como tachas negativas que impiden la contratación y, esto es lo relevante en este momento, como medidas administrativas que aunque limitan derechos no disponen de naturaleza sancionadora ${ }^{26}$.

\footnotetext{
${ }^{23}$ S. WILLIAMS-ELEGBE...., p.261

${ }^{24}$ C. PEREIRA....., p. 2

${ }^{25}$ Ibidem.

${ }^{26}$ Vid entre otras las sentencias del Tribunal Supremo del Reino de España de 28 de marzo de 2006, de31 de mayo de 2007 o de 18 de mayo de 2011, de
} 
Es conveniente anotar que estas prohibiciones se adoptan en garantía del interés general por lo que cuando éste esté en peligro por obvias razones de competitividad del mercado o de elevado riesgo del derecho al trabajo de personas que poco o nada tienen que ver con la causa de exclusión o de la prohibición, se podrá rehabilitar, tras un severo y riguroso examen de la prevención de daños futuros, al incurso en exclusión o prohibición para contratar.

Las recientes Directivas europeas de 2014 establecen la exclusión obligatoria de los procesos de contratación pública de aquellos candidatos y licitadores que hubieran sido condenados por sentencia judicial firme en determinados casos. En efecto, la exclusión obligatoria de los contratistas, de los operadores económicos, de los licitadores, se produce cuándo los poderes adjudicadores hayan comprobado o tengan constancia de alguna forma de que han sido condenados mediante sentencia firme fundada en participación en una organización delictiva, en corrupción, en fraude, en delito de terrorismo o delito ligado a actividades terroristas, en blanqueo de capitales o financiación del terrorismo, o en trabajo infantil u otras formas de trata de seres humanos. Esta obligación de exclusión, que es imperativa para los poderes adjudicadores tal y como señala el artículo 57.1 de la directiva 24 de 2014 de contratación pública, y el artículo 38.4 de la Directiva sobre concesiones, se aplicará también cuando el condenado mediante sentencia firme sea un miembro del órgano de administración, de dirección o de vigilancia del operador económico o tenga poderes de representación, decisión o control en el mismo.

Tal prohibición obligatoria para contratar por causa de corrupción es, desde luego, una forma de preservar los principios generales que presiden la contratación pública asegurando con ello una real competencia en las adjudicaciones. Pero también, y sobre todo, es un instrumento preventivo del combate a la corrupción ${ }^{27}$.

Sin perjuicio del reproche penal, que es cierto y no admite discusión, solo faltaría, la prohibición para contratar del artículo 57.1 de la Directiva de contratación pública tiene una relevante naturaleza preventiva ${ }^{28}$ y también una obvia aflicción para el contratista que le provoca daños a su reputación y, por ende, perjuicios económicos al dejar de contratar con la propia Administración ${ }^{29}$.

MEDINA ARNAIZ reconoce que estas prohibiciones suponen un paso adelante en la lucha contra la corrupción pero advierte que su puesta en práctica se enfrenta a dificultades que complican su aplicación ${ }^{30}$. En concreto, señala esta profesora que los efectos de estas prohibiciones se desvirtúan ante cuestiones tan concretas como pueden ser la falta de calificación común respecto de los elementos integradores de las infracciones penales de las que traen causa las exclusiones, la falta

\footnotetext{
${ }^{27}$ El Libro Verde de 2011 sobre modernización del mercado europeo se refiere a esta doble naturaleza de las prohibiciones obligatorias para contratar al señalar que la exclusión de los licitadores por motivo de corrupción $y$, en general, por falta profesional (inhabilitación) es un instrumento idóneo para castigar y prevenir los comportamientos profesionales ilicitud. El reproche jurídico y la prevención de la corrupción deben ir siempre unidos porque el combate a esta lacra social ha de realizarse desde esquemas compatibles y complementarios.

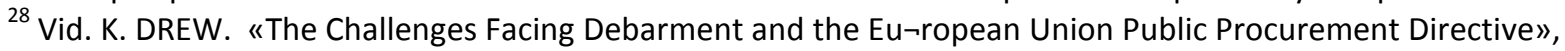
en la obra colectiva Fighting Corruption and Promoting Integrity in Public Procurement, Or-ganisation for Economic Co-operation and Development (OECD), Paris, 2005, pp. 267-276.

${ }^{29} \mathrm{Cfr}$. V. HOLLARD, L'exclusion des marchés publics (Annexe au rapport sur le projet de réforme du Code penal), Chambre de Commerce et d'Industrie de Paris, Paris, 1989

${ }^{30} \mathrm{~T}$. MEDINA ARNAIZ, Instrumentos jurídicos frente a la corrupción en la contratación pública: perspectiva europea y su incidencia en la legislación española, capítulo VI........, p.324
} 
de conocimiento de las condenas que implican la prohibición, la falta de reconocimiento en todos los Estados miembros de responsabilidad penal o la ausencia de un régimen procesal específico que posibilite las condenas ${ }^{31}$.

También se produce la exclusión automática de un operador económico o contratista cuándo el poder adjudicador tenga conocimiento, párrafo 2 del artículo 57 de la Directiva de contratación pública, de que tal operador o contratista haya incumplido sus obligaciones en lo referente al pago de impuestos o cotizaciones a la seguridad social y que ello haya quedado establecido en una resolución judicial o administrativa firme y vinculante. En efecto, podrán ser excluidos por esta causa cuando el poder adjudicador pueda demostrar por cualquier medio adecuado que el operador haya incumplido sus obligaciones tributarias o con la seguridad social. En el primer caso, en el número 1 del artículo 57, la exclusión es automática, imperativa, en el segundo supuesto es facultativa para el poder adjudicador. En estos casos, se levanta la exclusión cuando el operador económico haya cumplido sus obligaciones de pago o celebrado un acuerdo vinculante con vistas al pago de sus impuestos.

Estas exclusiones, razonables y lógicas para garantizar un mercado íntegro, equitativo y razonable, pueden ser excepcionadas por los Estados miembros de la Unión Europea, dice el párrafo 3 de este precepto para los casos expuestos anteriormente (corrupción, fraude... incumplimiento de obligaciones tributarias o laborales) por razones imperiosas de interés público como puede ser la salud pública o la protección del medio ambiente. Estamos en presencia de facultades propias de los poderes adjudicadores que de oficio pueden, si estiman que existen causas imperiosas de interés público, de interés general, levantar estas prohibiciones. El precepto "ad exemplum" se refiere a la salud pública o a la protección del medio ambiente, pero podría pensarse razonablemente en que, por ejemplo, la exclusión se excepcione cuándo se encuentre en grave peligro la publicidad y la concurrencia inherente a un sistema de mercado digno de tal nombre.

En estos casos, la decisión del órgano competente habrá de estar suficientemente motivada en razones concretas de interés general pues este concepto es compatible con el Estado de Derecho cuándo se expresa en lo concreto y de forma sólidamente argumentada. Pensemos, por ejemplo, en una desproporcionada restricción de ofertas que ponga en cuestión la capacidad del poder adjudicar de seleccionar con arreglo a buenos servicios a buenos precios. O también, podemos reflexionar acerca de la exclusión de un contratista con miles de trabajadores cuya prohibición se ha debido única y exclusivamente a la conducta delictiva del área comercial o de la presidencia o dirección general.

Los poderes adjudicadores en el seno de la Unión Europea pueden excluir, por sí mismos o a petición de los Estados miembros, a los licitadores en los supuestos a los que se refiere el párrafo 4 de este artículo 57 de la directiva. A saber, cuándo el poder adjudicador pueda demostrar por cualquier medio apropiado que se hayan incumplido las obligaciones en materia medioambiental, social o laboral; cuándo el operador económico ha quebrado o está sometido a un procedimiento de insolvencia o liquidación, si sus activos están siendo administrados por un liquidador o por un tribunal, si ha celebrado un convenio con sus acreedores, si sus actividades empresariales han sido suspendidas o se encuentra en cualquier situación análoga resultante de un procedimiento de la

\footnotetext{
${ }^{31}$ Ibidem.
} 
misma naturaleza (en este caso se puede levantar la exclusión a iniciativa de un Estado miembro si el poder adjudicador comprueba que el operador económico estará en condiciones de ejecutar el contrato) ; cuando el poder adjudicador pueda demostrar por medios apropiados que el operador económico ha cometido una falta profesional grave que pone en entredicho su integridad; cuando el poder adjudicador tenga indicios suficientemente plausibles de que el operador económico ha llegado a acuerdos con otros operadores económicos destinados a falsear la competencia; cuándo no pueda resolverse con medios menos restrictivos un conflicto de interés; cuándo no pueda remediarse por medios menos restrictivos un falseamiento de la competencia derivado de la participación previa de los operadores económicos en la preparación del procedimiento d contratación; cuándo el operador económico haya mostrado deficiencias significativas o persistentes en el cumplimiento de un requisito de fondo en el marco de un contrato público anterior, de un contrato anterior con una entidad adjudicadora o de un contrato de concesión anterior que hayan dado lugar a la terminación anticipada de ese contrato anterior, a indemnización por daños o perjuicios o a otras sanciones comparables; cuando el operador económico haya sido declarado culpable de falsedad grave al proporcionar la información exigida para verificar la inexistencia de motivos de exclusión o el cumplimiento de los criterios de selección, haya retenido información o no pueda presentar los documentos justificativos requeridos; cuándo el operador económico haya intentado influir indebidamente en el proceso de toma de decisiones del poder adjudicador, obtener información confidencial que pueda conferir ventajas indebidas en el procedimiento de contratación o proporcionar negligentemente información engañosa que pueda tener influencia determinante en las decisiones relativas a exclusión, selección o adjudicación.

En los supuestos del párrafo primero del artículo 57, las exclusiones son imperativas, mientras que en los casos del párrafo 4 de dicho precepto de la Directiva e contratación pública las exclusiones son facultativas para los poderes adjudicadores, que para aplicarlas deberán motivarlas adecuadamente. Así lo señala, para salir de dudas, el mismo párrafo 5 del precepto al que nos referimos.

La Unión Europea parte de la premisa de la existencia de un mercado abierto, plural, competitivo. Por eso la propia Directiva de contratación termina el régimen de las exclusiones para contratar reconociendo las llamadas técnicas de self-cleaning, los compromisos de integridad o probidad que pueden ser necesarios cuándo, efectivamente, se pongan en cuestión las más elementales reglas que deben caracterizar al sistema de mercado en economías presididas, como es el caso de la Unión Europea, por los principios del Estado social y democrático de Derecho.

Las nuevas Directivas de 2014 reconocen la posibilidad de excepcionar la aplicación de las exclusiones obligatorias a través de las medidas de autosaneamiento o de self-cleaning. Eso sí, siempre desde la óptica del principio de proporcionalidad, que exige que las prohibiciones no excedan de lo que sea apropiado o adecuado para lograr las finalidades establecidas en las Directivas en cuya virtud, como señalan ARROWSMITH, PRIESS y FRITON, se podrá eximir su aplicación a través de medidas de autocorrección cuando se pruebe que los candidatos o licitadores excluidos de participar en la licitación por concurrir en ellos un motivo de exclusión han adoptado medias eficaces para 
corregir las consecuencias de un comportamiento ilícito e impedir de manera efectiva que este se vuelva a repetir ${ }^{32}$.

Las finalidades de las Directivas aluden, es lógico, a los principios sobre los que descansa la propia Unión Europa. Es decir, a los principios de libre circulación de mercancías y servicios, de transparencia, de igualdad y prohibición de la discriminación, de proporcionalidad. Pues bien, el principio de proporcionalidad es el que mejor explica y justifica la adopción, en determinados casos, de estas medidas de autosaneamiento.

En efecto, las prohibiciones para contratar no pueden exceder de lo que es adecuado y necesario para cumplir las finalidades de las Directivas. Si realmente se comprueba que la causa de la exclusión o la prohibición ya no tiene sentido por haberse eliminado a base de implementar determinadas medidas internas en la empresa y así lo entiende el poder adjudicador tras un riguroso y exigente análisis y evaluación, como estas prohibiciones o exclusiones no son de naturaleza punitiva, entonces podría de forma excepcional levantarse dicho impedimento.

La Unión Europea, pues, a través de estas Directivas, se muestra favorable a la recuperación de credibilidad y fiabilidad perdida por un contratista que ha incurrido en una causa de prohibición o exclusión para contratar, si es que el poder adjudicador comprueba fehacientemente que el operador económico ha dispuesto las medidas de self-cleaning adecuadas para volver a merecer la condición de contratista capacitado para contratar con la Administración pública. Se reconoce, por tanto, en el Derecho Comunitario Europeo que operadores económicos penalizados, incursos en prohibición para contratar, puedan ejercer de nuevo su derecho a participar en licitaciones siempre y cuando hayan adoptado medidas adecuadas para reparar los perjuicios ocasionados y para evitar e impedir la realización de nuevos actos ilícitos.

La autorización de medidas autocorrectoras implica excepcionar la regla de la imposibilidad de contratar a contratistas incursos en causas de prohibición o exclusión siempre que a juicio del poder adjudicador, ejercicio de una potestad discrecional, hayan adoptado medidas eficaces y efectivas para corregir las consecuencias de un comportamiento ilícito de forma que éste presumiblemente no se vuelva a repetir.

La clave, a nuestro juicio, reside en el juicio de proporcionalidad que realizará el poder adjudicador para levantar o no la prohibición. El acto administrativo de rehabilitación en que consiste técnicamente el autosaneamiento supone el levantamiento de una prohibición por razones de interés general. Es la remoción de un obstáculo que impide el ejercicio de un derecho preexistente que no se puede realizar por la concurrencia de una determinada causa. Una vez que esta desaparece, siempre de acuerdo con el interés general, que debe ser concreto y motivado, entonces la prohibición pierde su razón de ser.

El principio de proporcionalidad, como bien sabemos, surge para limitar la arbitrariedad. Siendo la arbitrariedad todo ejercicio de poder irracional, realizado sin sometimiento a las reglas de la

\footnotetext{
${ }^{32}$ S. ARROWSMITH-H.J. PRIESS-P. FRITON«Self-Cleaning as a Defence to Exclusions for Misconduct-An Emerging Concept in EC Public Procurement Law?» PPLR, vol. 18 (6), 2009, pp. 257-282. En Alemania y Austria las medidas de self-cleaning son aceptadas mientras que, por el contrario, en Francia y Grecia las Autoridades competentes en materia de contratación no consideran aceptables estas medidas autocorrectoras o de autosaneamiento.
} 
recta razón, resulta que la proporcionalidad se mueve en el ámbito de la racionalidad y reclama que el poder de la Administración sea adecuado al fin previsto en la norma que atribuye capacidad de obrar a la misma Administración pública. La proporcionalidad convoca a la adecuación entre medios y fines, a la coherencia y congruencia entre medios y fines. De forma que un ejercicio de poder desproporcionado significa que la acción concreta desborda la finalidad de la misma. Es decir, el juicio de proporcionalidad se refiere a la medida en que una acción es necesaria y adecuada para garantizar el fin establecido.

En materia de lus Puniendi, de Derecho penal y Derecho Sancionador, el principio de proporcionalidad, junto a la reserva de ley para tipos e infracciones, y al "favor libertatis", constituye uno de los principales elementos para resolver los problemas que se puedan plantear en esta materia. Por eso, hay que tener en cuenta para este juicio de ponderación en que ordinariamente se concreta el test de proporcionalidad el objetivo que se busca con la medida (eliminar la causa de la prohibición y evitar que se produzca en el futuro), si la medida es idónea para conseguir el fin (si el autosaneamiento favorece la publicidad, la concurrencia, la igualdad, la transparencia, la competitividad del mercado y, fundamentalmente, que el poder adjudicador pueda seleccionar de entre varias ofertas la que contribuya a la mejora de las condiciones de vida de los ciudadanos) y si existe una medida menos gravosa para alcanzar el fin perseguido (si la autocorrección es la medida menos lesiva, en estos casos, para asegurar los fines de la contratación pública).

En materia de proporcionalidad hay que tener en cuenta otra consideración que es relevante en el tema que tratamos. Me refiero a que este principio juega en el marco de la legitimidad del actuar de la Administración pues garantiza que la actuación pública este en sintonía con el interés general. Más bien, se trata de que la medida elegida sea la que exige el interés general. Por tanto las medidas de autosaneamiento deben estar suficientemente justificadas, lo que se producirá, si es el caso, tras el examen que el poder adjudicador realiza de los compromisos del contratista incurso en la prohibición y siempre que se cumplan las condiciones que la Directiva establece para la viabilidad de estas medidas de self-cleaning. Además de la motivación, que ha de seguir unos elevados estándares pues el ámbito de la discrecionalidad es intenso y extenso, debe acreditarse que las medidas autorizadas no lesionan injustificadamente el derecho de otros contratistas, lo que no es el caso porque lo que provocan es un refuerzo de la concurrencia. En otras palabras, cuanta más intensa y extensa sea el poder discrecional, más intensa y extensa será la motivación de su ejercicio.

La actuación proporcional es, desde otra perspectiva, una manifestación de buena Administración pública. El número 16 de la Carta Iberoamericana de los derechos y deberes de los ciudadanos aprobada en el seno del CLAD por los ministros de Administración pública de la región, señala que uno de los principios sobre los que descansa la buena Administración pública es el de proporcionalidad, en cuya virtud las decisiones administrativas deberán ser adecuadas al fin previsto en el Ordenamiento jurídico, dictándose en un marco de justo equilibrio entre los diferentes intereses en presencia evitándose limitar los derechos de los ciudadanos a través de la imposición de cargas o gravámenes irracionales o incoherentes con el objetivo propuesto.

En la Unión Europea es fundamental que a través de un mercado objetivo y competitivo, los poderes adjudicadores puedan, en un marco de concurrencia, seleccionar las mejores ofertas de cara 
a poner a disposición de los ciudadanos las mejores obras y los mejores servicios. Por eso, la decisión administrativa sobre las solicitudes de self-cleaning de los contratistas han de incardinarse en este objetivo básico para lo cual es muy importante la búsqueda del equilibrio entre los interés en presencia y, sobre todo, no limitar de forma irracional e incoherente los derechos de los ciudadanos.

En estos casos, el órgano competente debe realizar un juicio de ponderación teniendo en cuenta la especial intensidad del interés general en el caso concreto y, tras el examen de la solicitud del contratista, intentar dictar la medida más idónea, más pertinente, más adecuada para alcanzar la finalidad prevista.

La UE ha reconocido esta excepción a las prohibiciones para contratar, conformándola, como veremos, como un derecho del contratista sometido a una revisión del poder adjudicador, que podrá autorizarla si entiende que se cumplen los requisitos a que ahora haremos o referencia o denegarla, en cuyo caso deberá motivar tal resolución.

La regulación de las medidas de self-cleaning no son una novedad novedosa de este momento. El Comité de las Regiones ya se refería a ellas en el 2000, algunos Estados de la UE, Alemania, Austria e Italia por ejemplo, contaban con ellas en sus legislaciones. El denominado Reglamento Financiero ${ }^{33}$ se refería expresamente a estas medidas de autosaneamiento y, en la actualidad, el artículo 57.6 de la Directiva de contratación pública -2014/24/UE- y el 38.9 de la Directiva de concesiones -2014/23/UE- contemplan estas medidas autocorrectoras de forma concreta.

En efecto, el párrafo 6 del artículo 57 de la Directiva comunitaria dispone que todo operador económico que se encuentre en alguna de las situaciones establecidas en los párrafos 104 del precepto "podrá presentar pruebas de que las medidas adoptadas por él son suficientes para demostrar su fiabilidad pese a la existencia de un motivo de exclusión pertinente. Si dichas pruebas se consideran suficientes, el operador económico no quedará excluido del procedimiento de contratación".

A tal efecto, sigue diciendo la Directiva en este parágrafo 6 " el operador económico deberá demostrar que ha pagado o se ha comprometido a pagar la indemnización correspondiente por cualquier daño causado por la infracción penal o la falta, que ha aclarado los hechos y circunstancias de manera exhaustiva colaborando activamente con las autoridades investigadoras y que ha adoptado medidas técnicas, organizativas y de personal concretas, apropiadas para evitar nuevas infracciones penales o faltas.

Las medidas adoptadas por los operadores económicos se evaluarán teniendo en cuenta la gravedad y las circunstancias particulares de la infracción penal o la falta. Cuando las medidas se consideren insuficientes, el operador económico recibirá una motivación de dicha decisión.

Los operadores económicos que hayan sido excluidos por sentencia firme de la participación en procedimientos de contratación o de adjudicación de concesiones no tendrán derecho a acogerse a la posibilidad prevista en el presente apartado durante el período de exclusión resultante de dicha sentencia en el Estado miembro en el que la sentencia sea ejecutiva"

\footnotetext{
${ }^{33}$ Reglamento (UE, Euratom) 966/2012, de 25 de octubre, artículo 1061 in fine.
} 
La Unión Europea prevé, pues, un sistema de inaplicación de las obligaciones por razones graves, imperiosas, de interés general, por motivos económicos, en virtud del juicio de proporcionalidad, por razones de regularización tributaria y a través de medidas de self-cleaning.

El juicio de la Administración contratante es un juicio prudencial basado en la proporcionalidad y teniendo presente la preeminencia del interés general en el caso concreto. Ciertamente, si la solicitud del contratista es seria, rigurosa y conduce al convencimiento por parte del poder adjudicador de que la causa de la prohibición ha desaparecido y que es razonablemente probable que no volverán a repetirse las conductas ilícitas, penales o administrativas, lo lógico y coherente es que se autorice la rehabilitación del contratista. Obviamente, se trata de una excepción a la regla general de la prohibición en la que está incurso el contratista por lo que el poder adjudicador debe ser especialmente estricto y severo en la apreciación de las razones esgrimidas por la empresa para obtener la rehabilitación.

Para que se produzca la rehabilitación del contratista incurso en prohibición o exclusión para contratar, según las Directivas de contratación de la UE para que recupere la fiabilidad y credibilidad perdida, es menester el pago o compromiso en relación con los daños causados, la colaboración con el esclarecimiento de los hechos y la adopción de medidas técnicas, organizativas o de personal que sean necesarias.

Es decir, el operador incurso en una de estas causales del párrafo 1 o 4 del artículo 57 de la Directiva, puede solicitar al poder adjudicador su rehabilitación a través de un compromiso en el que se documente fehacientemente que ya es un operador fiable. Entonces, si las pruebas se consideran suficientes por el poder adjudicador para acreditar la fiabilidad del licitador, este no quedará excluido.

Por tanto, se da carta de naturaleza a la voluntad de enmienda del licitador que se arrepiente de su conducta y promete firmemente, a través de pruebas fehacientes, que ha adoptado medidas adecuadas para ser considerado fiable por el poder adjudicador. El operador, pues, reconoce su culpa, y formula su propósito de la enmienda en virtud de pruebas que han de llevar al ánimo del poder adjudicador a reconocer le fiabilidad a partir de entonces.

Veamos los elementos que permiten el despliegue de la rehabilitación del contratista. Estas condiciones o requisitos deben darse todos conjuntamente pues son imprescindibles para acreditar la fiabilidad del contratista, especialmente en lo que se refiere a que en el futuro presumiblemente no se cometerán nuevos ilícitos.

Primariamente es necesaria la colaboración del contratista en el esclarecimiento de los hechos que desencadenaron la prohibición de contratar. Sin el esclarecimiento de los hechos, las medidas de autosaneamiento no estarán amparadas en la realidad y, por ende, será muy complicado para el poder adjudicador valorar su pertinencia y coherencia para evitar nuevas conductas ilícitas en el futuro.

La colaboración completa del contratista debe facilitar el conocimiento de las circunstancias en las que se cometieron los ilícitos y las responsabilidades de todas las personas y de todos los individuos involucrados, directa o indirectamente, en los hechos. Obviamente cuanto más rápido se puedan conocer los hechos y cuanta mayor claridad y complitud se pueda arrojar sobre lo acontecido más probabilidades de que se conceda la rehabilitación. En este sentido, si se pueden esclarecer los 
hechos de forma completa es más fácil para el poder adjudicador dimensionar adecuadamente las medidas de self-cleaning que sean más pertinentes ${ }^{34}$. Obviamente, la resistencia al esclarecimiento de los hechos, su ocultación o su manipulación son causas determinantes de la no concesión de la rehabilitación.

Una vez aclarados los hechos, la reparación de los daños efectivamente causados es más fácil así como la emisión del compromiso de su reparación. Para la concreción de los daños habrán de seguirse las reglas propias de los procesos jurídicos de indemnización de daños y perjuicios establecidos en la legislación de cada uno de los países de la UE.

Por lo que se refiere a la implementación de medidas técnicas, organizativas y de personal, es menester conocer la naturaleza de los hechos acontecidos para desde ellos proponer las medidas internas que permitan al contratista incurso en prohibición para contratar recuperar la fiabilidad y llevar al ánimo del poder adjudicador que tras su articulación tales conductas ilícitas presumible y razonablemente será muy difícil que vuelvan a repetirse al haberse desvanecido sus causas.

Estas medidas son de cara al futuro, para evitar que se repitan los hechos acontecidos. En realidad, una vez identificadas las causas de los ilícitos cometidos en el pasado, habrá que buscar la forma de invitar a salir de la empresa de forma inmediata, y explicada, a las personas, accionistas, directivos o empleados, que estuvieran involucrados en los hechos que desencadenaron los ilícitos cometidos. En el caso de los accionistas, es necesario adoptar las medidas que sean necesarias para que su salida sea real sin capacidad ni influencia sobre sus sucesores en la compañía ${ }^{35}$. Obviamente, el grado de desvinculación de la compañía de las personas involucradas en los ilícitos será proporcional a la intensidad de su responsabilidad en los hechos acecidos.

Las medidas de naturaleza técnica y organizacional se refieren específicamente a la implementación de acciones que impiden que los ilícitos cometidos se puedan volver a repetir. Son medidas de cara al futuro, medidas que solo se pueden implementar una vez que se hayan esclarecido delos hechos, indemnizado los daños, separado al personal responsable de la conducta ilícita. A partir de entonces, del momento en que se han identificado fehacientemente los problemas, es posible diseñar una estrategia concreta referida a medidas técnicas, estructurales y organizativas.

Siendo estas medidas de autosaneamiento de carácter eminentemente preventivo, el juicio prudencial que hará el poder adjudicador estará de alguna forma mediatizado por la naturaleza fuertemente preventiva de las medidas técnicas y organizativas presentadas por el contratista en el expediente de rehabilitación en que consiste el self-cleaning. Entre las medidas que pueden pensarse encontramos con planes de formación de ética orientados especialmente a prevenir las conductas ilícitas del pasado, la creación de unidades organizativas encargadas de supervisar determinadas políticas comerciales, el fortalecimiento control interno, el establecimiento de comités de ética formados por personas independientes, la periodicidad de la revisión de las medidas a adoptar. También es de tener en cuenta la existencia de órganos internos disciplinarios con procedimientos sancionadores gestionados por personal externo a la compañía. Es decir, toda la panoplia de

\footnotetext{
${ }^{34}$ C. PEREIRA...., p. 4

35 Ibidem
} 
acciones propias de los programas de Compliance analizadas con anterioridad. Eso sí, aplicados especialmente a la prevención de los concretos ilícitos acontecidos en el pasado.

Estas medidas de autosaneamiento parten, como hemos indicado, de una cultura preventiva en la lucha contra la corrupción que potencie el cumplimiento superando una visión única y excluyente de tipo punitivo, vigente hasta ahora en muchas latitudes. Esta cultura empresarial, y también administrativa, a favor del cumplimiento de las obligaciones contribuye de forma decisiva a evitar distorsiones de la competencia en los procedimientos de adjudicación. Además, la cultura de la autolimpieza facilita también una contratación más abierta pues no se limita la concurrencia y, además garantiza la efectiva realización del principio de proporcionalidad pudiéndose tomar en consideración las medidas correctivas puestas en marcha por los operadores económicos incursos en prohibiciones de contratar, demostrando, como dice MEDINA ARNAIZ, su fiabilidad ${ }^{36}$.

El operador económico incurso en prohibición o exclusión para contratar dispone de un derecho a que se examinen las medidas de cumplimiento por él adoptadas con vistas a u posible admisión al procedimiento de adjudicación. Por tanto, si los poderes adjudicadores comprueban la suficiencia y proporcionalidad de las medidas propuestas se removerá el obstáculo que impide el ejercicio de un derecho preexistente que es el de presentarse libremente a licitaciones públicas. Es un derecho del contratista sometido al juicio realizado por el poder adjudicador a través de un procedimiento administrativo contradictorio en el que se resolverá acerca de la fiabilidad y credibilidad de la propuesta planteada por el contratista. El procedimiento administrativo terminará con un acuerdo de rehabilitación o no, en cuyo caso habrá de motivarse convenientemente la negativa.

En efecto, la Directiva configura como un derecho de los operadores económicos el poder presentar pruebas de las medidas adoptadas para evitar nuevas infracciones penales o faltas para levantar la prohibición de contratar que les afecte, y lo hace de manera bastante clara, precisa e incondicionada $^{37}$. Se trata de un derecho de cuya operatividad depende el juicio de un órgano administrativo, normalmente el poder adjudicador, aunque la Directiva realmente no concreta su identidad, por lo que serán los Estados miembros en la trasposición de la Directiva quienes dispongan de capacidad para determinar la naturaleza de estos entes públicos llamados a evaluar la operatividad de estas medidas de autosaneamiento.

La cuestión sobre la identidad de los órganos públicos que han eventualmente de pronunciarse, tras el pertinente procedimiento administrativo, dependerá de la legislación de cada Estado miembro. Pueden ser desde los poderes adjudicadores particulares hasta órganos diferentes bien centrales bien descentralizados o, sería lo mejor, órganos colegiados integrados por personalidades independientes de reconocido prestigio nacional o internacional. Un análisis de las regulaciones existentes (Austria, Alemania, Reino Unido, Francia o Hungría) hasta el momento invita a pensar que serán los órganos de contratación concretos en cada caso quienes valorarán las medidas planteadas por los operadores económicos incursos en prohibición o exclusión para contratar. En el caso español, como apunta MEDINA ARNAIZ, aun cuando el problema todavía no se ha planteado ratione temporis ya que estamos en período de vacatio hasta abril de 2016, se puede

\footnotetext{
${ }^{36}$ T. MEDINA ARNAIZ, Las medidas de self-cleaning en la Unión Europea, Congreso Internacional de Contratación Pública, Universidad de Castilla-La Mancha, 21 de enero de 2016.

${ }^{37}$ M.A. BERNAL...., p. 417
} 
plantear una cierta complejidad cuando se compruebe que nuestra normativa contractual no es suficiente para dar cumplimiento a la obligación de resultado impuesta por la Directiva y se cuestione el efecto directo de los preceptos referidos a las medidas de self-cleaning ${ }^{38}$.

En el Reglamento de Ejecución (UE) 2016/7 de la Comisión Europea, de 5 de enero de 2016, por el que se establece el formulario normalizado del documento europeo único de contratación se exige una declaración formal por la que el operador económico afirma que no se encuentra incurso en causa de exclusión y que cumple los criterios de selección pertinente. Tal declaración, como es lógico, debe servir de prueba preliminar, en sustitución de certificados expedidos por Autoridades públicas o terceros. En concreto el documento a que nos referimos establece como criterios de exclusión: condenas penales, pago de impuestos o de cotizaciones a la seguridad social, insolvencia, conflictos de intereses o falta profesional, $\mathrm{u}$ otras causas de exclusión que pueden estar presentes en la legislación nacional.

En tal documento, en caso de condena penal, se pregunta a los operadores económicos: ¿ha adoptado medidas para demostrar su credibilidad pese a la existencia de un motivo pertinente de exclusión ("autocorrección")?. Si se contesta afirmativamente se solicita que se describan las medidas adoptadas. En caso de que se haya declarado al contratista culpable de una falta profesional grave, se preguntara si ello es cierto y en caso de ser así se pide que se detallen las medidas autocorrectoras adoptadas. En el mismo sentido se procede si el operador económico ha celebrado acuerdos con otras empresas destinados a falsear la competencia, si el operador lo reconoce, se le pregunta si ha adoptado medidas de autosaneamiento y, en caso, afirmativo, que las concrete.

En fin, el hecho de que entre nosotros, en España, como apunta BERNAL BLAY, todavía la autorregualdción no se encuentre regulada, constituye un serio obstáculo para que el autosaneamiento sea una realidad ${ }^{39}$. Es decir, resulta ineludible que las normas nacionales de trasposición acometan con urgencia el desarrollo sustancial y procedimental del artículo 57.6 de la Directiva 24 de 2014 concretando en qué consisten y que requisitos les son exigibles ex ante a los programas de Compliance para lograr su efectividad ex post ${ }^{40}$. Sin embargo, a pesar de la indeterminación del régimen jurídico, los Considerandos 71, 102 y 107 de la Directiva establecen algunos lineamientos a tener presente por los Estados miembros en la trasposición de la Directiva pues refieren a medidas que afecten al personal o a la organización, como la ruptura de todos los vínculos con las personas u organizaciones que participaron en las conductas ilícitas, medidas adecuadas de reorganización de personal, implantación de sistemas de información y control, creación de una unidad de auditoria interna para supervisar el cumplimiento y adopción de normas internas de responsabilidad e indemnización.

Estas previsiones establecidas en los Considerandos de la Directiva deben entenderse en un contexto de buena administración o buen gobierno, de forma y manera que, por ejemplo, la oficina de auditoría interna para supervisar el programa de Compliance si no está en manos de una personalidad o colegio de personalidades independiente, de poco o nada servirán. Es decir, las

\footnotetext{
${ }^{38}$ T. MEDINA, Las medidas....

${ }^{39}$ M.A. BERNAL..., p. 417

${ }^{40}$ Ibidem
}

Revista do Direito [ISSN 1982-9957]. Santa Cruz do Sul, v. 1, n. 51, p. 36-57, jan./abr. 2017. https://online.unisc.br/seer/index.php/direito/index 
medidas de autosaneamiento deben ser fiables, creíbles y, sobre todo, aptas idóneas para evitar ciertamente nuevas conductas ilícitas.

En este sentido, se debe subrayar, como hace BERNAL BLAY, que la Directiva se refiere a la adopción de medidas apropiadas - en inglés appropiate, en francés propres à, en italiano idonei- para evitar nuevas infracciones penales o faltas, una expresión diferente de la atenuante utilizada en el Código Penal, artículo 31 bis, que señala que tales medidas deben ser eficaces ${ }^{41}$. En el caso de las medidas de self-cleaning, su idoneidad se valora ex ante por el ente público competente, mientras que en el caso del Código Penal la eficacia de tales medidas solo es posible evaluarla ex post, una vez que se han adoptado, cuando se han cometido ya nuevos delitos, momento en el que carece ya de sentido entrar a valorar los efectos atenuantes ${ }^{42}$.

En marzo de 2015 se reformó en España el Código Penal con la promulgación de una Ley Orgánica y se dio nueva redacción al artículo 31 bis del Código, de manera que se exime de responsabilidad, no sólo se atenúa, a la persona jurídica de responsabilidad penal "que el órgano de administración haya adoptado y ejecutado con eficacia, antes de la comisión del delito, modelos de organización e inclusión que incluyen las medidas de vigilancia y control idóneas para prevenir delitos de la misma naturaleza o para reducir de forma significativa el riesgo de su comisión".

En relación con los órganos públicos que deben valorar las medidas propuestas por los contratistas incursos en prohibición para contratar, comparto la tesis de BERNAL BLAY cuándo señala que más que dejar estas decisiones en manos de los poderes adjudicadores concretos o de los órganos de contratación de cada contrato, es menester residenciar esta función en algún ente especializado en materia penal y administrativa que pueda unificar criterios en evitación de que si tal competencia se deja en manos de cada gestor público contractual se genere un ambiente de inseguridad $^{43}$.

Si fuera verdad que las causas de exclusión, o prohibiciones de contratar, quedaran con frecuencia sin verificar por los órganos de contratación, estas medidas de Compliance tendrían una eficacia muy limitada en relación con el acceso a un contrato público. Ahora bien, si resultara, que las causas de exclusión o prohibiciones para contratar se proyectaran también sobre los contratos en ejecución, entonces, como señala BERNAL BLAY, en el marco de la opción de resolución de un contrato por encontrarse el contratista en causa de exclusión en el momento de la adjudicación el autosaneamiento tendría más sentido ${ }^{44}$. En efecto, la legislación en materia de contratos debería comunicar las declaraciones de prohibición de contratar sobre aquellos contratos que la empresa se encontrara ejecutando en ese momento. Así, esta declaración se convertiría en prohibición de continuar la ejecución, incurriendo en causa de resolución que habría que incorporar a la legislación. Así, de esta manera, estos programas de autosaneamiento serían un estímulo para las empresas en el caso de que se pudiera levantar la prohibición de ejecución del contrato cuándos se considere que

\footnotetext{
${ }^{41}$ M.A. BERNAL...., p. 419

42 Ibidem

${ }^{43}$ M.A. BERNAL...., p.420

${ }^{44}$ M-A. BERNAL BLAY..., p. 421
} 
el programa de Compliance contemple medidas apropiadas para prevenir nuevas infracciones penales y administrativas ${ }^{45}$.

\section{REFLEXIÓN CONCLUSIVA}

La lucha contra la corrupción debe plantearse de forma integral. Desde la perspectiva punitiva y, también, dado el éxito de las políticas represoras, desde la prevención. La prevención de esta terrible lacra social invita a elevar la temperatura ética de la vida social, para lo cual es menester, desde luego, trabajar a fondo en los ámbitos educativos y familiares. Y, en el campo del combate a la corrupción en el marco de la contratación pública, a la vista de lo experimentado estos últimos años en diferentes países y ordenamientos, parece conveniente incluir como criterio de clasificación para las empresas contratistas acreditar solidos programas de cumplimiento. Además, en los casos de empresas castigadas por casos de corrupción. Siempre que se pueda verificar, a través de Autoridades independientes, de que se han eliminado las causas próximas y remotas de tales ilícitos, podría, excepcionalmente, y de acuerdo con argumentadas razones de interés general, rehabilitar a tales empresas siempre que ello sea beneficioso para que ciertamente los ciudadanos puedan disponer de las mejores obras y servicios públicos posibles.

La existencia de programas de cumplimiento y de medidas de autosaneamiento que están en vigor en el presente, especialmente en el marco de la Unión Europea, aconsejan que la dimensión preventiva y la perspectiva de la autorregulación regulada puedan ayudar a reducir la cuantiosísima factura que la corrupción pasa año a año a los ciudadanos.

\section{COMO CITAR ESSE DOCUMENTO:}

MUÑOZ, Jaime Rodríguez-Arana. Compliance y self-cleaning en la contratación pública (especial referencia al derecho comunitario europeo). Revista do Direito, Santa Cruz do Sul, v. 1, n. 51, jul. 2017.

${ }^{45}$ M.A. BERNAL BLAY...., p.422 